Ocean PP perspective, J. Marra

\title{
Ocean Productivity: A Personal Perspective Since the First Liege Colloquium
}

\author{
John F. Marra \\ Department of Earth \& Environmental Sciences \\ Brooklyn College of the City University of New York \\ Brooklyn, NY, USA
}

\begin{abstract}
I briefly review the changing dominant research agenda in ocean productivity over the time since the first Liege Colloquium, 44 years ago, and coincidentally, about when I started in oceanography. I then consider two lingering issues, the depth of the ocean's productive layer and the dynamics of dissolved organic carbon. These two topics are united through respiration, the former concerning autotrophic respiration, and the latter heterotrophic respiration.
\end{abstract}

The first Liege Colloquium was 44 years ago, in 1969, and I began my career in oceanography a few years after that, in 1972, as a graduate student. In those days, I remember the dominant research issue in ocean productivity was nutrient kinetics: how phytoplankton used nutrients, how nutrient concentrations affected growth, and how nutrient utilization and phytoplankton growth could be modeled using MichaelisMenten enzyme kinetics (e.g., Maclssac and Dugdale, 1972). Many were interpreting 


\section{Ocean PP perspective, J. Marra}

ecologically the Michaelis constant, Ks, which describes the affinity of a particular species or phytoplankton group to nutrient conditions in the ocean. At about the same time, Dick Eppley compiled the data for his temperature vs. maximum growth rate curve in cultured phytoplankton (Eppley, 1972). He came to Dalhousie (my alma mater) in summer of 1973, to present his research, and impressing at least one first-year graduate student. (He had been detailed from Scripps to Washington, D.C. at the Atomic Energy Commission; later the Dept. of Energy.) Both of these ideas, the manner in which nutrients were taken up by phytoplankton, and the 'Eppley curve,' as it came to be known, have withstood the test of time, and are embedded in most plankton models. We have since debated the parameters, but the nature of the relationships has remained.

As the 1970s ended, however, there were worries about the measurements of productivity we were making at sea. The ${ }^{14} \mathrm{C}$ method had become well established, and surveys of ocean productivity were being published, along with estimates of the productivity of the global ocean. The problem with the ${ }^{14} \mathrm{C}$ method was that it was too good. It was very sensitive and could be used in the most oligotrophic environments. But that also meant that it was difficult to evaluate with respect to other methods (see Marra, 2002). It was also easy to implement, and uptake always occurred. As a result, lots of data could be collected with little regard for veracity. 
Ocean PP perspective, J. Marra

It was (again) Dick Eppley who seemed to sense this most acutely. He found that he couldn't square the productivity numbers with how much was needed to support the rest of the ecosystem. Ocean trophodynamics seemed paradoxical. At the same time, microbiologists were establishing new methods and identifying a previously unrecognized food web, then called the 'microbial loop', an almost self-contained one of bacteria, microzooplankton, and very small phytoplankton. Anyway, in the very early 1980s, Dick brought together a group (fortunately, including me), into a program he called 'Plankton Rate Processes in Oligotrophic OceanS, or PRPOOS (and pronounced 'purpose').

PRPOOS, with two field programs in 1982 and 1985, made several important contributions. It was the first time (I believe) that Mike Landry used his dilution method in the tropical ocean (Landry et al., 1984). Michael Bender, with his student Karen Grande, introduced the oxygen-18 method to biological oceanography (Grande et al., 1987). Peter Williams (Williams et al., 1983) and Duncan Purdie (Williams and Purdie, 1991), for the first time, successfully used the light-dark bottle oxygen method in the oligotrophic ocean. In all our methods, we were very careful to follow the protocols introduced around that time by George Knauer and Steve Fitzwater (Fitzwater et al., 1982; see also Marra and Heinemann 1987). Introducing these methods was important also because it forced us to pay close attention to each step in our procedures, to ensure that our measurements did not inhibit or interrupt plankton processes. 
Ocean PP perspective, J. Marra

Communications from ship to shore, from the middle of the ocean back to the lab (or home!) was difficult in those days, but happened on occasion. From the cruise to the North Pacific Central Gyre in 1985, I remember speaking to Jim Ammerman, a colleague at the time, back at Lamont-Doherty, and telling him that if our measurements were representative, I thought we had about doubled ocean productivity. The PRPOOS program signified a turning point in biological oceanography. For the first time, plankton rate processes could be evaluated across many different methods. And PRPOOS defined what has become, I believe, a canonical value for primary production for the open ocean, $\sim 450 \mathrm{mg} \mathrm{C} \mathrm{m}^{-2} \mathrm{~d}^{-1}$.

Also, during the 1980s, changes were coming to optical oceanography. Ocean optics had pretty much always been the domain of physicists, if not physical oceanographers. Whereas biologists looked at the growth of particles in the ocean (microbes and phytoplankton being the most abundant), optical oceanographers looked at how those particles affected the absorption and scattering of light.

The interaction of particles and their fluid medium is a complex problem. There are many different kinds, shapes, and sizes of particles responding in different ways, with wavelength dependence, across the irradiance spectrum. There are two ways of describing optical properties in fluid media: the inherent optical properties are those 


\section{Ocean PP perspective, J. Marra}

defined by the nature of the medium and the particles themselves and are measured using a defined light source. The apparent optical properties are measured using solar radiation (at the angle the sun subtends in the sky) as the light source. Interestingly, the planktonic particles respond to apparent properties, but their subsequent growth or loss affects inherent properties.

That said, what happened in the 1980 s was that the optical oceanographers and biological oceanographers came together, the biologists to show how light affected particle growth, and the optical oceanographers to define the drivers (apparent properties) and the result (the inherent properties). It might not be too much of a stretch to say that the field of 'bio-optics' in the ocean was born in the 1980s, through programs such as Biowatt (Marra and Hartwig, 1984; Smith et al., 1989). The marriage of optics and biology, along with physical oceanography, was responsible for some significant advances to technology (such as a compact in situ fluorometer). The marriage also produced methods for observing the ocean at important time scales (Dickey et al., 1991) and that have now become a standard part of the oceanographic technological repertoire.

If the 1980s saw the marriage of biological with optical oceanography, during the 1990 s we all became biogeochemists. The reason was the Joint Global Ocean Flux Study, or JGOFS (see, http://www1.whoi.edu/). JGOFS was a 10-year program (1988-1998), and in 


\section{Ocean PP perspective, J. Marra}

the U. S. was sponsored by the National Science Foundation. Although the program had different components, the part where geochemists and biologists, along with physical oceanographers, worked in concert was on the so-called 'process studies.' These were oceanographic expeditions designed to understand the imbalances between atmospheric and oceanic $\mathrm{CO}_{2}$. These imbalances occurred in the North Atlantic during the spring bloom, the equatorial Pacific because of upwelling, the Arabian Sea with its intense monsoons, and the Southern Ocean because of its strong seasonality and seasonally changing ice cover. With JGOFS, the science of the ocean, and especially biological oceanography, became truly international. Whereas in the 60 s and 70 s we might have justified our science in terms of 'food from the sea', now it was the global carbon cycle, and the ocean's role in that. The 1990s was also the time when most of the autotrophic biomass in the ocean was recognized to be very small and prokaryotic (Waterbury et al., 1988), and the occasion of the first 'ocean experiment,' IRONEX, to test John Martin's iron hypothesis (Coale et al., 1996).

And late in the 1990s, there was ocean color! We could now 'see' the ocean as we never could from ships. One indication of the problem in describing spatial variability in the sea from ships came in the 1980 s with the Warm Core Rings program. I was told that at one workshop, many of those who had operated from shipboard quietly put their viewgraphs of results away after hearing from those who showed those ocean eddies from space. Even if things slowed down after JGOFS, satellites gave us the ocean at the 


\section{Ocean PP perspective, J. Marra}

global scale. Getting an ocean color signal is a very hard technical problem, and something the community had been working on since the Coastal Zone Color Scanner (CZCS). The CZCS was launched in 1978 as a 'proof-of-concept' mission. NASA chose to send it into orbit, even though many of the processing details for ocean color hadn't been worked out. That decision was the right one. The CZCS lasted much longer than its original anticipated 1-year lifetime, affording time to solve many of the technical problems. Oceanography is indebted to (what is now called) the Ocean Biology Processing Group at NASA Goddard: Gene Feldman, Chuck McClain, and others (e.g., Feldman et al., 1989; http://oceancolor.gsfc.nasa.gov/) who, from the Sea Wide-Fieldof-View Sensor (SeaWiFS) and later the Moderate Resolution Imaging Spectrometer (MODIS), showed us a surface ocean of sometimes astounding variability and beauty.

With the results of JGOFS, there was renewed interest in what happens to the organic carbon produced at the surface, and how it gets transformed in other parts of the ocean's ecosystem, particularly with depth. The first decade of the $21^{\text {st }}$ century also consolidated many of the findings of JGOFS. And by this time, we could detect some of the longer term, inter-annual changes that occur in the ocean, that before we perceived only dimly, thanks to the Hawaii Ocean Time Series (HOT) and the Bermuda Atlantic Time Series (BATS). It was appreciated that every year was not the same, and long-term changes to the ocean ecosystem, appreciated more by fisheries scientists, occurred in the plankton, sometimes toppling what we thought were 'paradigms' (Karl, 1999). The 


\section{Ocean PP perspective, J. Marra}

2000s were also the time that genomics and metabolomics came of age for oceanography. The microbial community in the ocean, so diverse, and so difficult to culture and identify, began to reveal its secrets through genomics.

So, the issues regarding productivity changed during the last 40 or so years, as oceanography underwent tremendous technological advances and matured as a science. Through all that time, over my career at any rate, the goal, the theme, the thread, remained the same: the "determination of the time-varying plankton productivity in the world ocean..." (Barber and Hilting, 2002).

Now I would like to touch on two lingering problems, issues that have been ignored, or glossed over, or (ahem) 'submerged.' And I am as guilty as everyone else. These issues are first, the depth of the euphotic zone, and second, the sources, nature, and sinks for dissolved organic carbon. Both of these issues have at their heart, respiration. The actual, biological, depth of the euphotic zone, or the productive layer in the ocean, depends on knowing autotrophic respiration. The key to the nature and variability of dissolved organic carbon depends on heterotrophic respiration. This year's Liege Colloquium is focused on primary productivity. Even so, I'll try to argue that a path towards understanding productivity means a comparable understanding of respiration, both autotrophic and heterotrophic. 
Ocean PP perspective, J. Marra

The Depth of the Euphotic Zone

Fig. 1 illustrates the problem. As the cartoon shows, the productive layer extends horizontally, bounded by coastlines, current systems, or biogeography, and is selfevident. Its depth, however, is essentially unknown. Thus, we are missing an important dimension in the ocean, the depth of the productive layer.

For optical oceanographers, the euphotic zone is simple: it's whatever they say it is. Optical oceanographers have adopted the common criterion of ' $1 \%$ ' of surface irradiance (usually, photosynthetic active radiation, or PAR), which we can write as $1 \%$ $E(0)(P A R)$. It was biological oceanographers, I think, however, who arrived at the $1 \%$ light level; in the words of John Ryther (1956), it "defines the depth below which no appreciable photosynthesis can occur." Ryther's definition was an approximation of what we call the "compensation depth," where gross photosynthesis is balanced by respiration. And physiologically, the compensation irradiance is the irradiance at the compensation depth. The compensation depth is the biological, and more appropriate, definition of the autotrophic productive layer. Every student learns the compensation depth in his or her first-year oceanography classes, but the sad truth is that it is never measured. We have merely, and meekly, accepted the ' $1 \%$ ' criterion because autotrophic respiration couldn't be measured. [Banse (2004) has recently discussed the issues surrounding the $1 \%$ light depth.] Some will argue that $1 \% E(0)(P A R)$ is good 
Ocean PP perspective, J. Marra

enough as an estimate of the compensation depth, because there is not much production to worry about deeper in the water column, anyway. Mathematically, areal primary production can be estimated using an indefinite depth integral of production as a function of depth, $\mathrm{P}(\mathrm{z})$. The compensation depth, however, is important in at least a couple of ways, not the least of which is defining the depth dimension to the ocean's productive ecosystem. Two ways the compensation depth is important that I will discuss here are, first, calculating Sverdrup's critical depth, and second, in estimating primary production from space.

The critical depth, as defined by Sverdrup (1953), is where areal gross photosynthesis = areal (autotrophic) respiration (see Fig. 2). The equation expressing the critical depth can be written,

$$
\frac{Z c r}{1-\exp (k \cdot Z c r)}=\frac{E\left(0^{-}\right)}{E c \bullet k}
$$

where $Z c r$ is the critical depth, $E\left(0^{-}\right)$is the irradiance just beneath the surface [roughly 94-98\% of that above the surface, $E\left(0^{+}\right)$, around mid-day], $E c$ is the compensation irradiance (at which gross photosynthesis is balanced by respiration), and $k$ is the vertical attenuation coefficient $\left(\mathrm{m}^{-1}\right)$. Eq. (1) is a transcendental, and therefore not easy to solve further. It turns out that the best way to arrive at $Z c r$ is to assume a value for $E c$ 


\section{Ocean PP perspective, J. Marra}

(with a given surface irradiance and a k). More importantly, the critical depth depends consequentially on the compensation depth, i.e., the depth where net production is zero. For these reasons, there have been very few actual tests of the critical depth idea, although it does have substantial intuitive appeal. A bloom will not occur unless photosynthesis exceeds respiration in the water column, given a certain depth of mixing.

One of the problems of Sverdrup's (1953) treatment is that he derives the equation based on physiology while the test he employs concerns changes to biomass, phytoplankton cell numbers collected at a weather ship over the course of several months in the early spring in the North Atlantic. This has led many to conclude that grazing should be included as a loss term in any analysis of the critical depth. Certainly, grazing will play a role in regulating the timing and magnitude of the spring bloom (e. g., Behrenfeld, 2010). However, phytoplankton will have the same physiology, the same ratio of photosynthesis to respiration, whether they are eaten or not. Thus, we have to differentiate between what might be a community compensation depth with the autotrophic compensation depth. The former will be shallower, since it includes other losses (grazing, heterotrophic respiration, sinking) besides autotrophic respiration (Regaudie-de-Gioux and Duarte, 2010). The autotrophic compensation depth, however, defines the productive layer from the standpoint of primary production, and that is, shall we say, 'critical.' 
Ocean PP perspective, J. Marra

The critical depth hypothesis has been questioned recently (e.g., Behrenfeld, 2010), but the idea that there will be a relationship between mixing, photosynthesis, and respiration that affects phytoplankton and production dynamics remains sound. The concept of the critical depth will still resonate as a means to evaluate bloom phenomena, life histories, and plankton dynamics in this era of climate change.

A second way in which the compensation depth is important is that if we know the depth of the euphotic zone, we have another avenue to estimate water column primary production from space. Thus we have the ' $\Psi$ ' algorithms. The parameter $\Psi$ is the water column production divided by the product of water column chlorophyll-a and surface irradiance. It can be written (Falkowski, 1981) as

$$
\Psi=\frac{\int_{t 0}^{t 1} \int_{z 10 \%}^{z 1 \%} P(t, z) d z d t}{\int_{z 100 \%}^{z 1 \%} B(z) d z \bullet \int_{t 0}^{t 1} E o(t) d t}
$$

where in this equation, $P$ is the rate of net primary production, $B$ is the quantity of chlorophyll-a, and Eo is the surface irradiance. $P$ is integrated over depth $(z)$ and time (here, represented by to to $t 1$ ), $B$ with depth only, and Eo with time only. And in this equation, $P$ and $B$ are explicitly integrated to the $1 \%$ light depth. The units of $\Psi, \mathrm{mg} \mathrm{C}{ }^{2}$ 
Ocean PP perspective, J. Marra

(mg Chlorophyll-a) $)^{-1}$ (mol photons) ${ }^{-1}$ led Platt (1986) to derive a simplification to the above equation, as

$$
\Psi=\alpha^{8} / 4 \cdot 6,
$$

where 4.6 refers to the natural $\log$ of $1 \%$, and $\alpha^{\beta}$ is the parameter for the initial slope of the photosynthesis v. irradiance relationship normalized to chlorophyll-a, that is, having the same units as $\Psi$. In both the Falkowski (1981) and Platt (1986) derivations, however, the depth of integration is the $1 \%$ light depth, even though autotrophic biomass is commonly found at deeper depths than that, as we shall see.

It happens that we can estimate phytoplankton respiration from incubations with ${ }^{14} \mathrm{C}$, using a technique developed by Dick Barber and myself (Marra and Barber 2004). This method requires three assumptions. First, over daytime and $24 \mathrm{~h}$ incubations, isotope is well mixed in intracellular pools so as to be respired as equally as ${ }^{12} \mathrm{C}$. Second, over these incubation times, the ${ }^{14} \mathrm{C}$ assimilation approximates most closely, net primary production (NPP). Finally, and this is the more difficult assumption to accept, daytime and nighttime respiration are equal. That ${ }^{14} \mathrm{C}$ is well mixed within the cell is readily recognized, as explained in Marra and Barber (2004). There is substantial literature to support the idea that ${ }^{14} \mathrm{C}$ estimates NPP, however, we have recently attempted an 
Ocean PP perspective, J. Marra

experimental test, essentially applying the dilution method (Landry and Hassett, 1982) to a ${ }^{14} \mathrm{C}$ uptake experiment. As shown in Fig. 3 , whether the seawater is diluted by $75 \%$ with particle-free water or not makes no difference to ${ }^{14} \mathrm{C}$ uptake in a dawn-to-dusk incubation. (A $24 \mathrm{~h}$ experiment, not shown, has identical results.) We interpret this to mean that grazing is unimportant in ${ }^{14} \mathrm{C}$ uptake experiments, agreeing with theoretical arguments (Laws et al., 2000).

Whether daytime and nighttime respiration are equal is difficult to determine. However, this equality is what is assumed in light-dark bottle oxygen flux incubations (Laws et al., 2000). And mitochondrial respiration has been found to be the dominant kind for phytoplankton (Geider, 1992). The actual data, where we correct NPP for respiratory loss, and then compare that value to independent estimates of gross primary production (GPP), look pretty good (Fig. 4). We have concluded that departures from the 1:1 line are probably caused by methodological errors as much as anything else (Marra. 2009).

Accepting that the method described in Marra and Barber (2004) is valid, we can use it to find the depth of the euphotic zone as the compensation depth. We have done productivity profiles (in situ) on a cruise a few years ago to the summertime Northwest Atlantic, selecting incubation depths based on the profile of in vivo fluorescence (and not light depths). It turns out that at the end of $24 \mathrm{~h}$, we can either use the depth where 


\section{Ocean PP perspective, J. Marra}

NPP is estimated to intersect a 'zero' value, or the depth where gross production equals respiration. The details, that is, the methods, calculations, etc. can be found in Marra et al. (2014). I show one profile from that cruise here (Fig. 5), but which typifies the results we obtained.

On that cruise, we found that the compensation depth is always deeper than the $1 \%$ light depth. That this should be true has been speculated for some time, and at times evaluated (e.g., Laws et al., 1987). However, here, the interesting finding is that the compensation depth coincides with the base of the fluorescence maximum. The euphotic zone encompasses all the autotrophic biomass. Second, we found that it also roughly coincides with the depth of penetration of $1 \%$ of blue light, that is $\operatorname{Ed}(490)$, which for this station is $74 \mathrm{~m}$. We realize that this might exchange one optical criterion for another. However, ocean color satellites have a data product for the attenuation of irradiance at $490 \mathrm{~nm}$, so there is the possibility that we could estimate the depth of the euphotic zone from space.

These data (see Marra et al., 2014) are preliminary and limited, but provocative. To see how these same depth criteria - base of the autotrophic biomass, $1 \% \operatorname{Ed}(490)$ - apply to another ocean, we accessed data from the Hawaii Ocean Time Series (HOT) in the North Pacific. Without respiration measurements we cannot calculate a compensation depth, but there are in vivo fluorescence and optical data for many of the stations. Fig. 6 is one 
Ocean PP perspective, J. Marra

example, profiles of in vivo fluorescence and $\operatorname{Ed}(490)$. The HOT location, typically, has much deeper fluorescence maxima than the Atlantic. Here, the bottom of the fluorescence profile is not at $1 \% \operatorname{Ed}(490)$, but nearer to $0.1 \%$. Is the euphotic zone deeper here? Are the phytoplankton in the North Pacific Subtropical Gyre adapted to lower irradiances? Also note the slight increase in attenuation deeper, as a result of the increased attenuation associated with the chlorophyll maximum.

Overall, we think we are on the right track. Now we need a field program to look at these issues specifically. Knowing the actual depth of the euphotic zone is liberating!

Dissolved Organic Carbon: Sources and Sinks

The other side of the respiration problem is heterotrophic. Most of the heterotrophic respiration in the plankton is bacterial, and the food source for bacteria is dissolved organic carbon (DOC). It has been estimated that $50 \%$ of primary production eventually finds its way through the dissolved pool, the dissolved primary production, or DPP. DPP is not typically measured in productivity experiments. Using the light-dark bottle protocol for oxygen or carbon dioxide fluxes will include it, but not differentiate it from particulate production. And of course, particle production methods (changes in particle attenuation, for example; Marra 2002) will not directly measure the dissolved fraction. Measurements of ${ }^{14} \mathrm{C}$ assimilation can distinguish dissolved primary production, but may 


\section{Ocean PP perspective, J. Marra}

underestimate it because the released compounds are rapidly utilized by bacteria (Cherrier et al., 1996; Cherrier and Bauer, 2004), and then measured as particulate production. Often, for the open ocean, DPP is small enough at daily time scales that it is within the error of the method. And finally, something that hasn't been considered is that satellite sensors for ocean color do not capture DPP.

If not knowing how to estimate the magnitude of DPP is bad enough, we have very little information on the nature of DOC, whether it is comprised of carbohydrates, amino acids or peptides, or organic phosphorus compounds, or how labile or bio-available the organic compounds are. The dynamics of DOC underlie the workings of the microbial loop (Azam et al., 1982), which dominates energy and material transfer in the open ocean. Cherrier et al. (this volume) describe experiments where diatoms, in nutrient rich situations (coastal waters, in culture), however, release significant amounts of DOC, and which seems to be preferentially utilized by resident bacteria.

\section{Concluding Remarks}

The strides made in ocean productivity studies over the last 40 or so years have left problems in their wake, or shunted them aside. There remain many opportunities for further advances, and the papers in this volume are testament to that. I've discussed two issues that are sometimes thought to be on the fringe of productivity studies, and 
Ocean PP perspective, J. Marra

related to each other by the central process of respiration. By 'fringe' I mean that by the usual methods, these contributions to quantifying primary production can be thought of as small. For example, the increase in primary production attendant on an increase in the depth of the euphotic zone is calculated to be in the range of about $10 \%$ (see Marra et al., 2014). However, much has recently been written concerning whether the open ocean is net autotrophic or net heterotrophic (e.g., Duarte et al., 2013; Williams et al., 2013). Others believe in a metabolic balance because the measurements hover around zero. If the depth of the euphotic zone is deeper than traditionally assumed, the increase in primary production favors net autotrophy. If bacterial respiration of DOC is important, it may be that dissolved primary production has been underestimated, complicating the view of the metabolic balance. We need to take a better look at both the issues of the actual, biological, depth of the ocean's productive layer and the quantity of fixed carbon that gets diverted to dissolved pools. For the former, it would help if productivity measurements were conducted with in situ incubations, and not done according to 'light depths.'

Acknowledgements. I thank Marina Levy and Marilaure Gregoire, organizers of the $45^{\text {th }}$ Liege Colloquium, for giving me the opportunity to contribute. I thank the two reviewers for generously providing comments that improved the manuscript. ON DEQUE was supported by the National Science Foundation (collaborators were R. Vaillancourt, B. 
Ocean PP perspective, J. Marra

Hargreaves, and V. Lance). The Hawaii Ocean Time Series (HOT) data are available through http://hahana.soest.hawaii.edu/hot/hot_jgofs.html.

References

Azam, F., Fenchel, T., Field, J.G., Gray, J.S., Meyer-Reil, L.A., Thingstad, F., 1983. The ecological role of water-column microbes in the sea. Mar. Ecol. Prog. Ser., 10, 257263.

Banse, K., 2004. Should we continue to use the $1 \%$ light depth convention for estimating the compensation depth of phytoplankton for another 70 years? Limnology and Oceanography Bulletin 13, 49-52.

Barber, R.T., Hilting, A.K., 2002. History of the study of plankton productivity, pp. 16-43. In: Phytoplankton productivity: carbon assimilation in marine and freshwater environments.. Williams P. J. leB., Thomas, D.N., Reynolds C.S.,. Blackwells, Oxford, UK.

Behrenfeld, M.J., 2010, Abandoning Sverdrup's Critical Depth Hypothesis on phytoplankton blooms. Ecology, 91, 977-989.

Cherrier, J., Bauer, J.E., Druffel, E.R.M., 1996. Utilization and turnover of labile dissolved organic matter by bacterial heterotrophs in eastern North Pacific surface waters. Mar. Ecol. Prog. Ser. 139, 267-279. 
Ocean PP perspective, J. Marra

Cherrier, J., Bauer, J.E., 2004. Bacterial utilization of transient plankton-derived

dissolved organic carbon and nitrogen inputs in surface ocean waters. Aquatic.

Microb. Ecol. 35, 229-241.

Coale, K.H., Fitzwater, S.E., Gordon, R.M., Johnson, K.S., Barber, R.T., 1996. Control of community growth and export production by upwelled iron in the equatorial Pacific Ocean. Nature 379, $621-624$.

Dickey, T., Marra, J., Granata, T., Langdon, C., Hamilton, M., Wiggert, J., Siegel, D.A., Bratkovich, A., 1991. Concurrent high resolution optical and physical time series observations in the Sargasso Sea during the spring of 1987. Journal of Geophysical Research 96, 8643-8663.

Duarte, C.M., Regaudie-de-Gioux, A., Arrieta, J.M., Delgado-Huertas, A., Agusti, S., 2013. The Oligotrophic Ocean Is Heterotrophic. Ann. Review of Marine Science 5, 551589.

Eppley, R.W., 1972. Temperature and phytoplankton growth in the sea Fishery Bulletin 70, 1063- 1085.

Falkowski, P.G., 1981. Light-shade adaptation and assimilation numbers. J. Plankton Res. 3, 203-216.

Feldman, G., Kuring, N. Ng, C., Esaias, W., McClain, C. Elrod, J. Maynard, N., Endres, D., Evans, R., Brown, J., Walsh, S., Carle, M., Podesta, G., 1989. Ocean color: Availability of the global data set. Eos, Transactions American Geophysical Union 70, 634-641. 
Ocean PP perspective, J. Marra

Fitzwater, S.E., Knauer, G.A., Martin, J.H., 1982. Metal contamination and its effect on primary production measurements. Limnology and Oceanography 27, 544-551.

Geider, R.J., 1992. Respiration: taxation without representation? Pp. 333-360. In: Primary productivity and biogeochemical cycles in the sea. Ed. By P.G. Falkowski and A. Woodhead. New York, Plenum.

Grande, K.D., Williams, P.J. LeB., Marra, J., Purdie, D.A., Heinemann, K., Eppley, R.W., Bender, M.L., 1989. Primary production in the North Pacific gyre: a comparison of rates determined by the ${ }^{14} \mathrm{C}, \mathrm{O}_{2}$ concentration and ${ }^{18} \mathrm{O}$ methods. Deep-Sea Research, Part A 36, 1621-1634.

Karl, D.M., 1999. A sea of change: biogeochemical variability in the North Pacific Subtropical Gyre. Ecosystems 2, 181-214.

Landry, M.R., Haas, L.W.Fagerness, V.L., 1984. Dynamics of microbial plankton communities: experiments in Kaneohe Bay, Hawaii. Marine Ecology-Progress Series $16,127-133$.

Landry, M.R., Hassett, R.P., 1982. Estimating the grazing impact of marine microzooplankton. Marine Biology 67, 283-288.

Laws, E.A., Ditullio, G., Redalje, D., 1987. High phytoplankton growth and production rates in the North Pacific Central Gyre. Limnology and Oceanography 32, 905-918. Laws, E.A., Landry, M.R., Barber, R.T., Campbell, L., Dickson, M.-L., Marra, J., 2000. Carbon cycling in primary production bottle incubations: Inferences from grazing 
Ocean PP perspective, J. Marra

experiments and photosynthetic studies using ${ }^{14} \mathrm{C}$ and ${ }^{18} \mathrm{O}$ in the Arabian Sea. DeepSea Research II 47, 1339-1352.

Maclsaac, J.J., Dugdale, R.C., 1972. Interactions of light and inorganic nitrogen in controlling nitrogen uptake in the sea. Deep-Sea Research 19, 209-232.

Marra, J., 2002. Approaches to the measurement of plankton production, pp. 78-108 In: Phytoplankton productivity: carbon assimilation in marine and freshwater ecosystems. Ed. by Williams, P.J.leB., Thomas, D.N., Reynolds, C.S., Blackwell Science, Oxford UK.

Marra, J., 2009. Net and gross productivity: weighing in with ${ }^{14} \mathrm{C}$. Aquat. Microb. Ecol. $56,123-131$.

Marra, J., Barber, R.T., 2004. Phytoplankton and heterotrophic respiration in the surface layer of the ocean. Geophysical Research Letters 31, L09314.

Marra, J., Hartwig, E.O., 1984. Biowatt: A study of bioluminescence and optical variability in the sea. Eos, Transactions American Geophysical Union 65, 732-733.

Marra J., Heinemann, K., 1987. Primary production in the North Pacific Central Gyre: some new measurements based on ${ }^{14} \mathrm{C}$. Deep-Sea Research 34, 1821-1829.

Marra, J., Lance, V.P., Vaillancourt, R.D. Hargreaves, B.R., 2014. Resolving the ocean's euphotic zone. Deep-Sea Research I 83, 45-50.

Platt, T., 1986. Primary production of the ocean water column as a function of surface light intensity, algorithms for remote sensing. Deep-Sea Res. 33, 149-163. 
Ocean PP perspective, J. Marra

Regaudie-de-Gioux, A., Duarte, C.M., 2010. Compensation irradiance for planktonic community metabolism in the ocean. Global Biogeochemical Cycles 24, GB4013

Ryther, J.H., 1956. The measurement of primary production. Limnology and Oceanography 1, 72-84.

Smith, R., Marra, J., Perry, M.J., Swift, E., Baker, K.S., Buskey, E., Kiefer, D.A., 1989, Bioluminescence and optical variability in the Sea: A photon budget for the upper ocean. Limnology and Oceanography 34, 1673-1693.

Sverdrup, H., 1953. On conditions for the vernal blooming of phytoplankton. Journal Conseil Internationale Exploration de la Mer 18, 287-295.

Williams, P.J.leB., Heinemann, K.R., Marra, J., Purdie, D.A., 1983. Comparison of ${ }^{14} \mathrm{C}$ and $\mathrm{O}_{2}$ measurements of phytoplankton production in oligotrophic waters. Nature 305, 49-50.

Williams, P.J.LeB., Purdie, D.A., 1991. In vitro and in situ derived rates of gross production, net community production and respiration of oxygen in the oligotrophic subtropical gyre of the North Pacific Ocean. Deep-Sea Research Part A 38, 891-910. Williams, P.J.LeB., Quay, P.D., Westberry, T.K., Behrenfeld, M.J., 2013. The Oligotrophic Ocean Is Autotrophic. Annual Review of Marine Science 5: 535-549. 
Ocean PP perspective, J. Marra

Figure Captions

Fig. 1. Productive layer schematic illustrates that while land boundaries and biogeographic provinces define the horizontal extent of ocean productivity, the vertical dimension is unknown.

Fig. 2. Critical Depth schematic, after Sverdrup (1953), showing net primary production $(P)$, gross primary production $(G)$, and autotrophic respiration $(R p)$ as a function of depth. Here, $\mathrm{G}$ is a linear function of irradiance, and so declines exponentially with depth in the water column. Also noted is the relationship between the depth of mixing (where temperature is constant) and the biological parameters leading to the critical depth and the compensation depth (where $\mathrm{G}=\mathrm{R}$, or $\mathrm{P}=0$ )

Fig. 3. The results from an experiment where carbon assimilation was measured in $100 \%$ seawater (y-axis) and in sub-samples that were diluted with particle-free water to $25 \%$, multiplied by 4 (x-axis, " $25 \%$ SW* 4 "), for dawn-to-dusk ( $12 \mathrm{~h}$ ) incubations. The data points represent the average of three replicates, and the error bars are the standard deviations. Units are $\mathrm{mg} \mathrm{C} \mathrm{m}^{-3} 12 \mathrm{~h}^{-1}$. Dashed line 
Ocean PP perspective, J. Marra

represents 1:1 correspondence. Details of the procedure are in Marra et al. (2014).

Fig. 4. Data comparing two independent gross photosynthesis estimates. The $y$-axis, "Corrected C Assim." is the daytime carbon assimilation plus twice the overnight dark loss of carbon in ${ }^{14} \mathrm{C}$ incubation experiments, and converted to oxygen units using a photosynthetic quotient of 1.4. The $x$-axis is independently measured ${ }^{18} \mathrm{O}$ gross primary production. Units for both axes are $\mu \mathrm{M} \mathrm{O}_{2} \mathrm{~d}^{-1}$. The linear regression (solid line) has an $r^{2}=0.83$, with a $95 \%$ confidence limit $= \pm 0.05$. Dashed line represents a 1:1 relationship. The intercept is not significantly different from zero. Adapted from Marra (2009).

Fig. 5. An in vivo fluorescence profile from the program ON DEQUE, station 1706 in the northwest Atlantic in July 2008. The stations on this cruise were stably stratified with depth. The ellipse indicates the depth in the profile of $1 \%$ of surface irradiance. The arrow points to the depth in the profile where $G=R(P=0)$, the compensation depth. Other profiles showing the same relationship can be found in Marra et al. (2014).

Fig. 6. An in vivo fluorescence profile from the HOT program, HOT cruise 121, along with a contemporaneous downwelling irradiance $[\operatorname{Ed}(490)]$ profile. Indicated on 


\section{Ocean PP perspective, J. Marra}

the fluorescence profile are the $1 \%$ and $0.1 \%$ of $\mathrm{Ed}(490)$ just below the surface.

The straight line is a fit to the irradiance data by assuming a water column averaged attenuation coefficient. Data are courtesy of the JGOFS HOT program, http://hahana.soest.hawaii.edu/hot/hot_jgofs.html. 


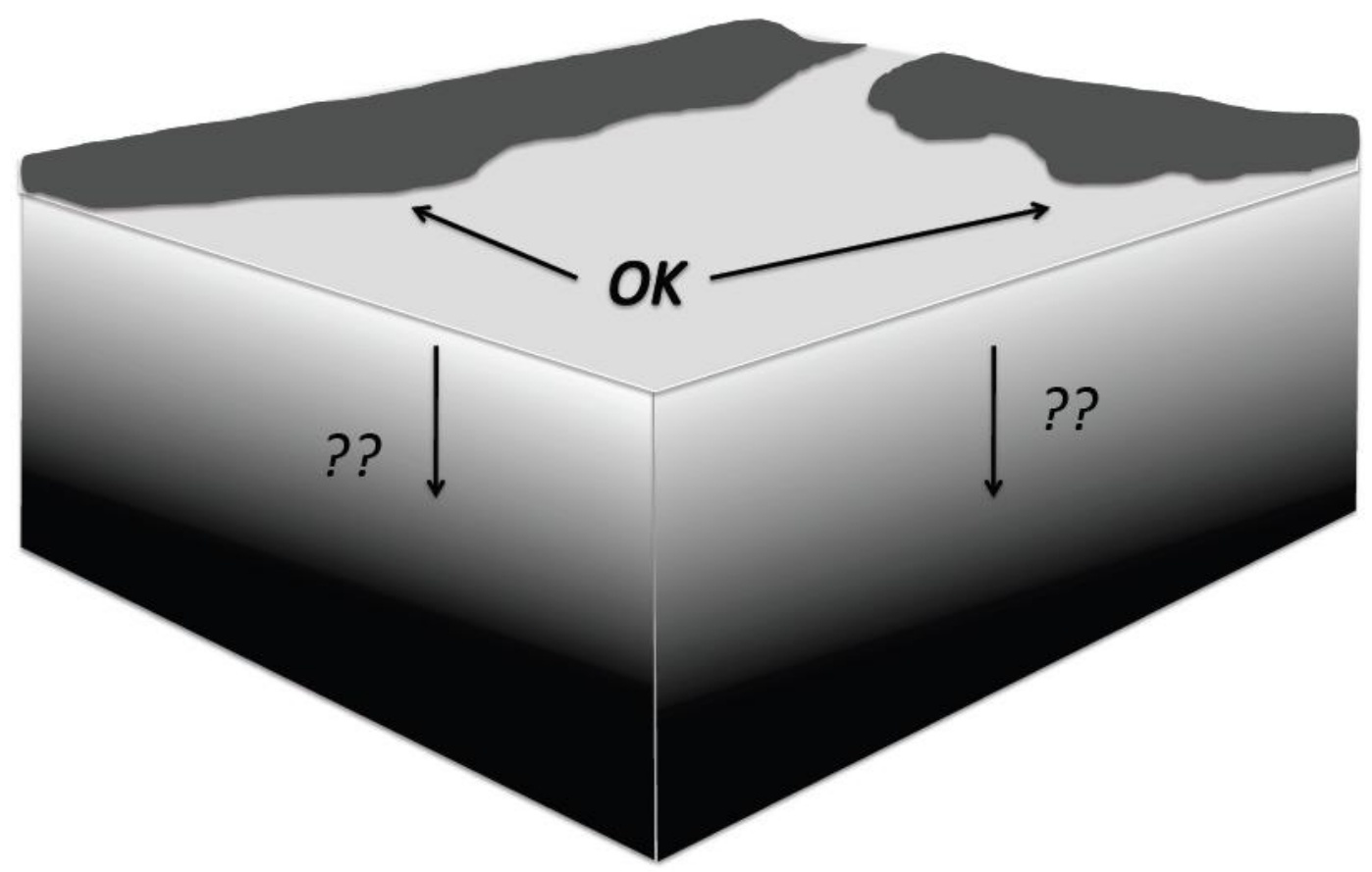

Figure 1 
Ocean PP perspective, J. Marra

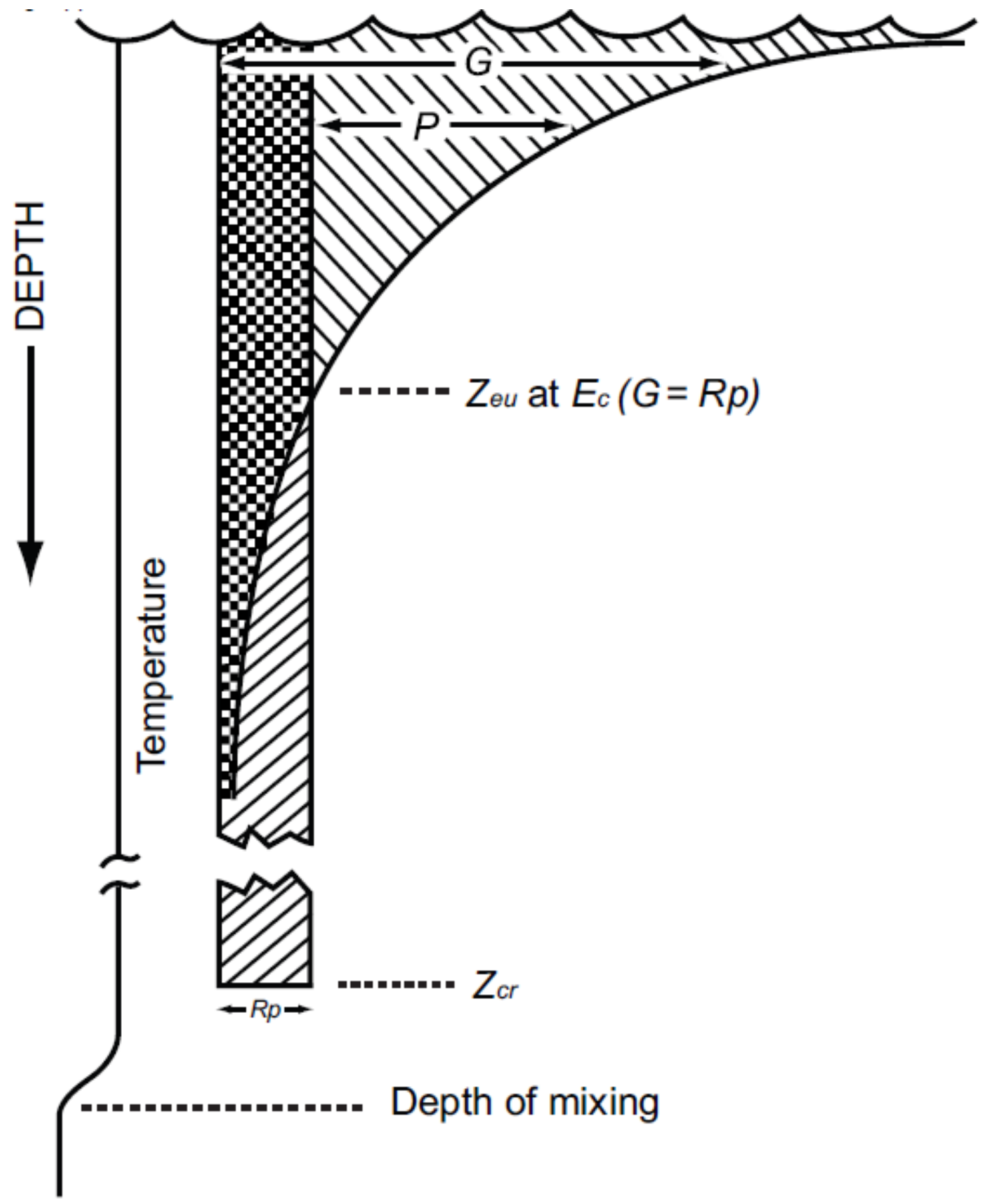

Figure 2 
Ocean PP perspective, J. Marra

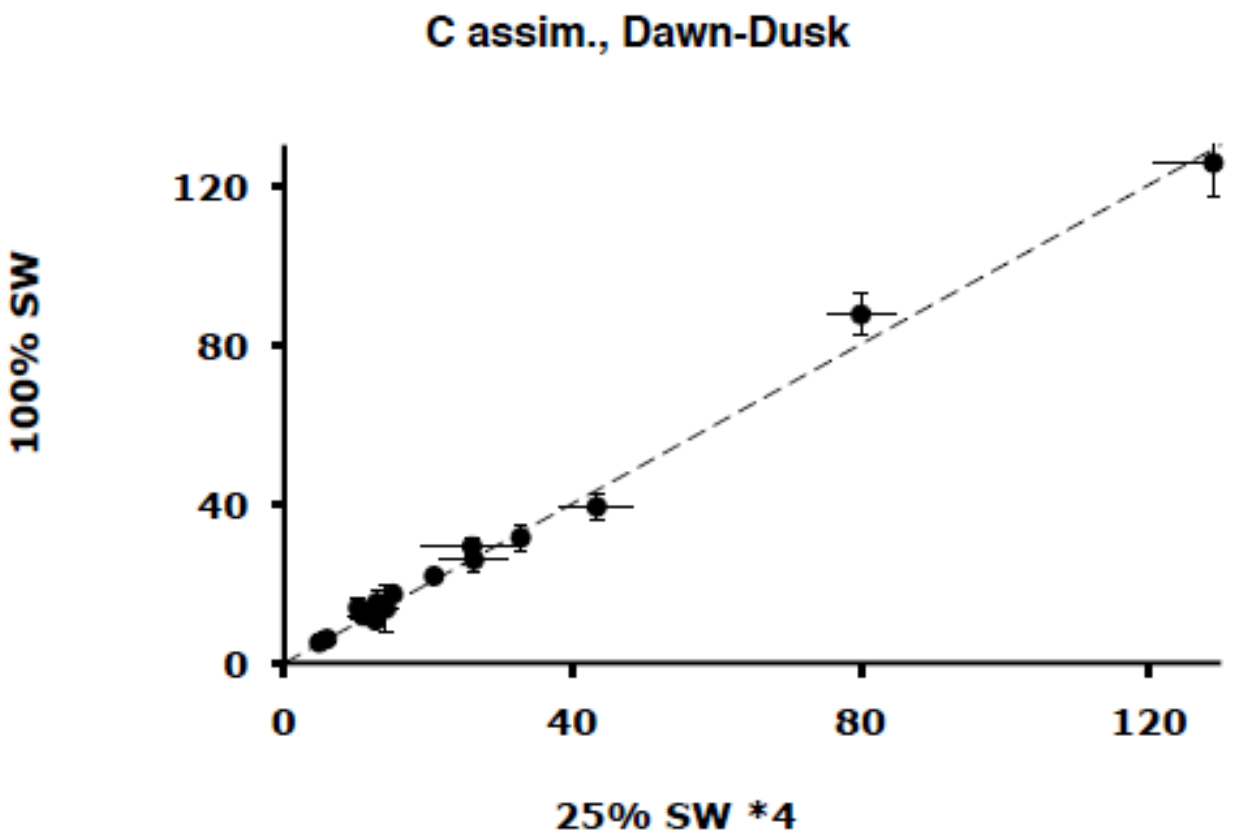

Figure 3 
Ocean PP perspective, J. Marra

15

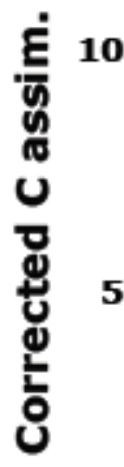

0

$\mathbf{0}$

5

10

15

Gross Primary Production

Figure 4 
Ocean PP perspective, J. Marra

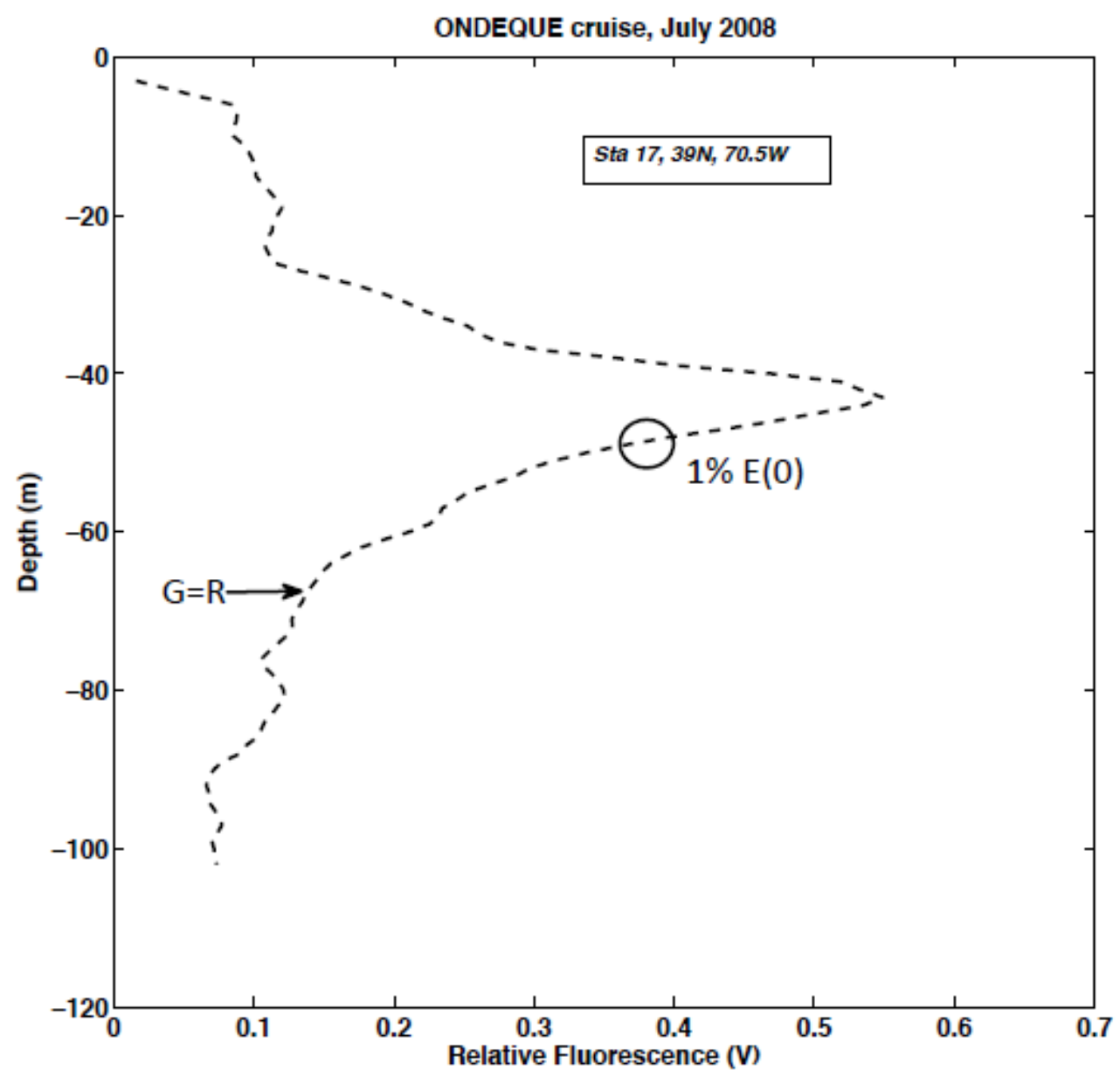

Figure 5 
Ocean PP perspective, J. Marra

Hawaii Ocean Timeseries cruise 121, Dec2000

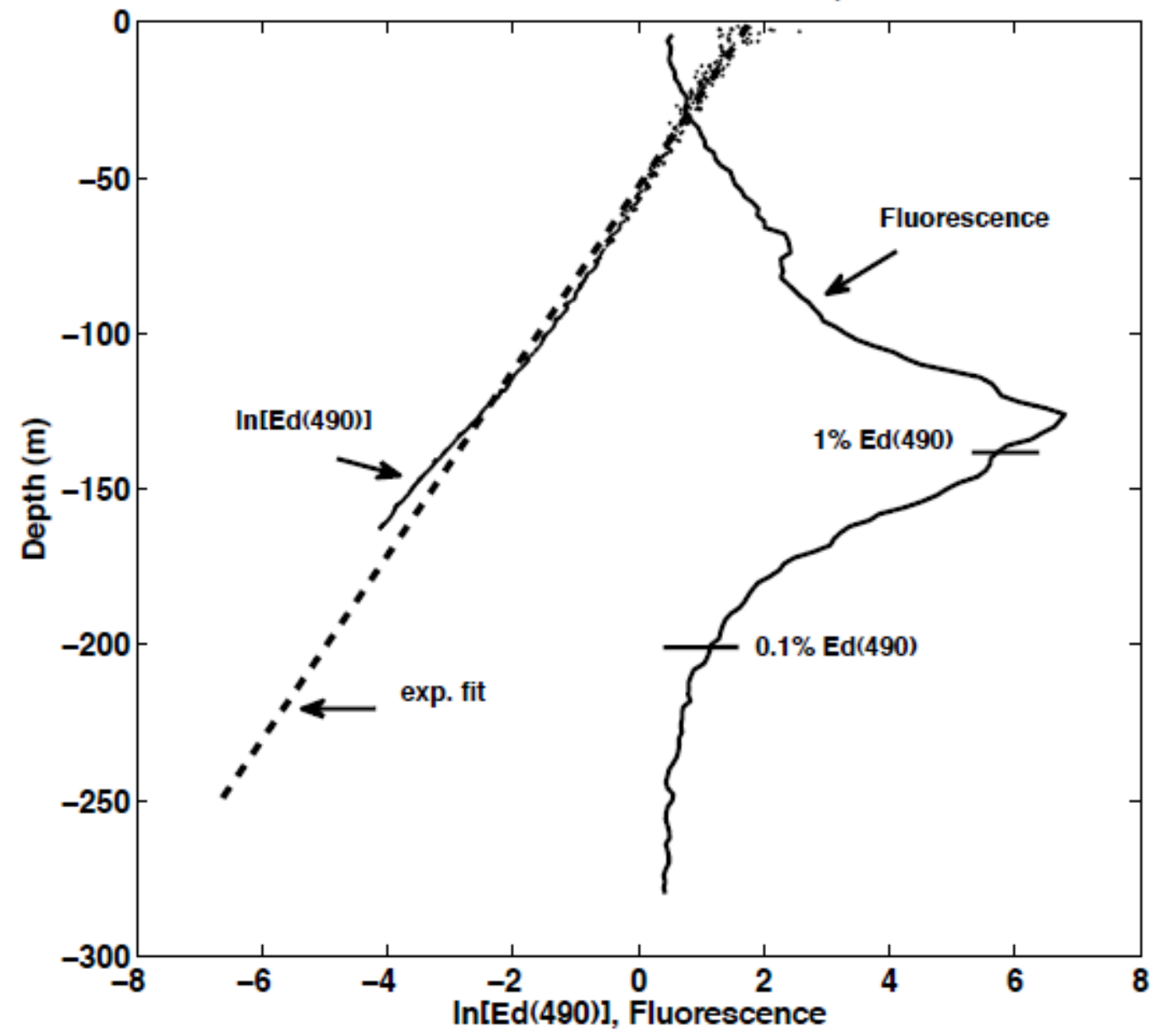

Figure 6 